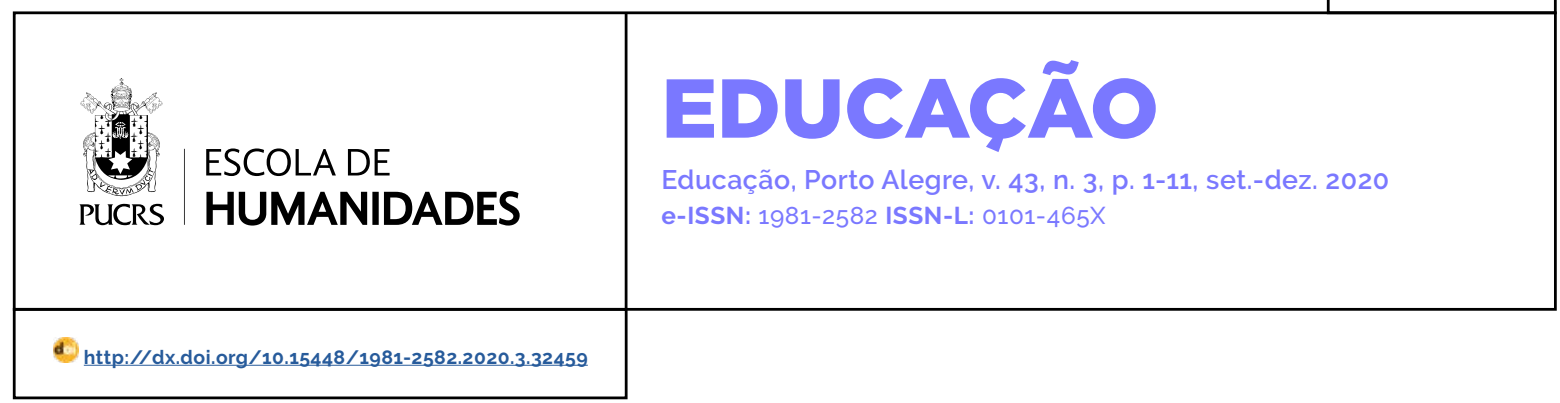

OUTROS TEMAS

\title{
A metodologia do entre, o educador e a assessoria na prevenção do autismo
}

\author{
The between methodology, the educator and the advisor in the prevention of autism \\ La metodología del entre, el educador y la asesoría en la prevención del autismo
}

\section{Dorisnei Jornada da \\ Rosa $^{1}$}

orcid.org/0000-0001-6022-2164

dorisneijornada@yahoo.com.br

Andrea Gabriela Ferrari ${ }^{1}$ orcid.org/0000-0002-42623033 ferrari.ag@hotmail.com

Recebido em: 7/11/2018. Aprovado em: 19/11/2020 Publicado em: 8/3/2021.
Resumo: O artigo trata da importância da metodologia do entre, de Homi Bhabha (1998) utilizada em uma pesquisa de mestrado. O objetivo visa refletir sobre os efeitos da intervenção transdisciplinar na prevenção do autismo, a partir da experiência de educadores e de assessoria em educação precoce no campo da educação infantil. Para tanto, utiliza os resultados de uma pesquisa realizada com duas crianças, dos zero aos três anos de idade e seus educadores, que foi constituida por quatro tempos: o tempo de criação do trabalho de assessoria EP/PI/SMED, a detecção dos sinais de autismo nos bebês, a avaliação psicanalitica dessas crianças aos três anos de idade e a escrita da pesquisa. Os resultados indicam que houve mudanças na posição discursiva dos educadores, produzindo efeitos não apenas educativos, mas estruturantes e terapêuticos, possibilitando a saída do risco de autismo e a retomada dos processos psíquicos constitutivos nas duas crianças.

Palavras-chave: metodologia entre, psicanálise, educação infantil, assessoria, autismo.

Abstract: This article is about the importance of the 'In-Between' Methodology, by Homi Bhabha (1998), utilized in a master's research. The point is to reflect on the effects of a transdisciplinary intervention in prevention of autism, based on the experience of educators and Advisors in Early Education in the field of early childhood education. Therefore, the results of a research will be used; Said research was conducted with two children, from zero to three years old, and their teachers, being constituted in four periods: The creation of the EP/PI/SMED accessory, the detection of signs of autism in babies, the psychoanalytic evaluation of these three-year-old children and writing down the results. The results indicate that there were changes in educators' discursive position, producing not only educational, but also structuring and therapeutic effects, allowing the exit of the risk of autism and the resumption of the constitutive psychic processes in the two children.

Keywords: 'in-between' methodology, psychoanalysis, child education, accessory, autism.

Resumen: El escrito trabaja la importancia de la metodología del entre de Homi Bhabha (1998) utilizada en una investigación de maestria. El objetivo es reflexionar sobre los efectos de la intervención transdisciplinar en la prevención del autismo, a partir de la experiencia de educadores y asesoria en educación temprana en el campo de la educación infantil. Para tanto, utiliza los resultados de una investigación realizada con dos niños de cero a tres años y sus educadores y fué constituida por cuatro tiempos: el tiempo de la creación del trabajo de asesoría EP/PI/SMED, la detección de señales de autismo en los bebés, la evaluación psicoanalítica de esos niños cuando tenían tres años de edad y el escrito de la investigación. Los resultados indican que hubo modificaciones en la posición discursiva de los educadores y produjo efectos educativos y también estructurantes y terapéuticos que permitió salir del riesgo de autismo y la retomada de los procesos psíquicos constitutivos en los dos niños.

Palabras clave: metodología entre, psicoanálisis, educación infantil, asesoria, autismo. 
Este artigo é resultado dos impasses e dos caminhos da escrita da dissertação de mestrado da primeira autora, realizando-se, sob orientação da segunda, colocados na perspectiva do relato de um trabalho de inclusão. Na dissertação foi relatado o trabalho de assessoria em educação precoce (EP) e psicopedagogia inicial (PI) com duas crianças com risco de autismo e suas educadoras em uma escola de educação infantil. O recurso metodológico utilizado para enlaçar as etapas do trabalho foi o entre (Bhabha, 1998). O entre foi pensado como um recurso metodológico inspirado na ideia de híbrido desenvolvida por Homi K. Bhabha (1998) em O Local da Cultura. O autor propõe um espaço híbrido para o trabalho com as diferenças culturais.

Em nossa pesquisa, o entre foi pensado um fort'da (Freud,1920/2010a), isto é, um entrar e sair transitando em um lugar e em outro, entre dois campos: psicanálise e educação, tanto infantil, como especial. Nossa pesquisa realizou um trânsito entre o campo da Educação e o da Psicanálise, enlaçando o educar com a clínica de bebês e crianças pequenas com sinais de risco de autismo. A utilização do entre (Bhabha, 1998) ajudou-nos nas reflexões sobre os impasses e os movimentos estruturais em crianças que eram consideradas de inclusão pela escola de educação infantil, quando ocorreram giros discursivos operados pelos educadores - ao produzirem atos de semblante ${ }^{2}$ das funções materna, paterna, terapêutica e pedagógica. Essas funções passaram a exercer para essas crianças caminhos e possibilidades para não fixação da estrutura psíquica denominada autismo.

\section{A história e a escrita de uma pesquisa: um fort'da entre os tempos de 1991 a 2018, o entre os campos e a educação estruturante}

Colocar na perspectiva clínica a dimensão enigmática presente na atividade da pesquisa e da construção do conhecimento coloca em cena a experiência de cada um como pesquisador e como formador de novos pesquisadores, não escamoteando nesses processos os obs- táculos e desafios, partindo do postulado de que a pulsão de saber nos anima intensamente ou nos paralisa, tornando assim indissociável o processo de produto. Essa perspectiva de compreensão sobre a produção de conhecimento nos obriga a refletir como nossas diferentes abordagens, metodologias e procedimentos, além da validade científica própria a cada epistemologia, comportam zonas cegas provenientes da maneira como nos relacionamos com o mundo e com o saber. (Diniz, 2017, p. 39)

Nossa atividade de pesquisa caracterizou-se por desdobramentos nos processos de intervenção. Testemunhamos o que Diniz (2017) nos ensina sobre pesquisa: a reinvenção singular que se confronta no coletivo, com outras produções singulares, multiplicando, como um caleidoscópio, as diversas possibilidades de arranjos, encontros e de desencontros. O pensamento dessa autora possibilitou-nos abordar os impasses e os desafios na construção das questões da pesquisa, que perpassam campos de tensão entre a Psicanálise, a Educação Infantil, e o trabalho de assessoria EP/PI. A assessoria EP/PI é composta por profissionais da educação especial da Secretaria (Rosa, 2011) de formação variada e visa à problematização das concepções presentes referentes ao entendimento de seus educadores - de como a criança pequena de zero a seis anos, com transtorno em seu desenvolvimento - aprende e se desenvolve na escola infantil, até a articulação que essa produz na socialização dessa e em sua estruturação como sujeito.

Meira (2001) diz que ao incluir as crianças com transtornos em seus desenvolvimentos não se trata de enunciar a palavra de ordem: "escola para todos", mas sim que esses todos possam ser registrados em suas singularidades, enquanto sujeitos. É neste sentido que as contribuições da Psicanálise entram em jogo quando se trabalha a inclusão. Esse processo de inclusão é lento e trata-se da inserção da criança no campo social, pois é na escola infantil que os pequenos ensaiam seus primeiros passos de separação da vida familiar em direção aos laços sociais. Após anos de atuação da primeira autora, entre o campo da Educação Especial e da Educação Infantil com

\footnotetext{
2 Semblante é o que se localiza no lugar do agente, como disparador do discurso, o qual é também um lugar ou posição nos quatro discursos de Lacan (1969-1970/1992) como equivalente ao status do significante, decorrente da produção discursiva.
} 
crianças de inclusão, traduzir e transliterar do campo da experiência para o desenvolvimento de uma pesquisa sobre o tema se delinearam como tempos de recriar, registrar e compreender essas intervenções nos seus efeitos discursivos.

Diniz (2017) afirma que, em toda pesquisa, há um acerto de contas do pesquisador com seu passado, desde a escolha do objeto a ser pesquisado até o seu produto final. A autora aponta ainda que - queiramos ou não - sempre haverá uma tensão entre o saber do pesquisador e o dos sujeitos envolvidos, pois são atravessados por elementos inconscientes e fantasmáticos; lembremos aqui que o sujeito do inconsciente é o do sujeito-pesquisador. Transparecendo essa questão, a escolha do entre se deu, a posteriori, ao considerarmos o aparecimento desse significante na pesquisa, como algo que poderia romper o binarismo dos impasses metodológicos entre dois campos do conhecimento: a Educação e a Psicanálise. De forma a aliviar essa tensão, associamos nossas formulações à base teórica do entre-lugares, de Homi K. Bhabha (1998).

\section{O entre-lugares}

Conforme Bhabha (1998) o entre-lugares é um espaço de transdisciplinaridade, em que, além do trans ou entre, não há um novo horizonte, nem um abandono do passado, mas sim um "au-delà, um fort'da, um para lá e para cá" (Bhabha,1998, p. 27). O ponto que caracteriza a sua abordagem é um sujeito nos entre-lugares, nos excedentes da soma das partes da diferença (expressas como raça, classe, gênero, exclusão etc.). O autor, com a intenção de forçar a lógica binária a inscrever-se em outro espaço, propõe a categoria de negociação. Não se trata, portanto, do verdadeiro ou do falso, nem do bom ou do mau, nem do certo ou do errado, pois seriam binarismos. Trata-se de tensionar para que cada negociação seja um processo de tradução e de transferência de sentido, no qual a categoria do hibridismo e da diferença cultural pode ser convocada como construção de um algo a mais, como um transitar entre um e outro campo. Esse transitar é chamado de entre-lugares, trazendo para discussão a proposta de uma reflexão epistemológica sobre qual o lugar e de quais práticas se apropria o sujeito da enunciação na cultura atual, visto que esse conceito pode ser pensado como uma possibilidade de os diferentes viverem na modernidade. O autor nos aponta vários exemplos para reinscrever comunidades fronteiriças ou excluidas, transformadas frequentemente em alegorias de alienação social.

Schäffer (1999) considera Homi K. Bhabha um autor que redefine as posições da cultura em categorias como entre-lugares, entre-tempos, hibridismos. Ela ainda ressalta que o deslocamento da diversidade cultural enquanto objeto epistemológico é substituido pela diferença cultural, o que nos ajuda a entender a contemporaneidade, introduzindo um outro espaço cultural. Então, há um trabalho fronteiriço, que ressoa como um espaço intermediário de intervenção no aqui e no agora, aliados a uma estética hibrida.

O trabalho fronteiriço da cultura exige um encontro com o novo, que não seja parte do contido em um passado e presente. Ele cria uma ideia do novo com ato insurgente de tradição cultural. Essa arte não apenas remonta o passado com causa social ou precedente estético: ela renova o passado, reconfigurando-o como um entre-lugar contingente, que inova e interrompe a atuação do presente. O 'passado-presente' torna-se parte da necessidade, e não da nostalgia de viver. (Bhabha, 1998, p. 27)

\section{O entre e a pesquisa}

Esse elemento - o entre - ofereceu um enlace transdisciplinar entre a Educação e a Psicanálise, permitindo um trânsito nos campos de assessora e de pesquisadora sem, com isso, perder a inquietude ao educar e a tratar bebês e crianças pequenas com sinais de risco de autismo. No seguimento do trabalho de pesquisa, o entre (Bhabha, 1998) foi enlaçado às reverberações das memórias do percurso anterior de assessora em educação precoce (EP) e em psicopedagogia inicial (PI). ${ }^{3}$

\footnotetext{
3 Atendimento instrumental crianças com problemas de desenvolvimento de três a seis anos. Nomenclatura e conceitualização utilizada pelas equipes de EP/PI/SMED de Porto Alegre.
} 
No intuito de tecer os tempos e os lugares, as informações para a pesquisa foram coletadas em uma Escola de Educação Infantil, onde a primeira autora atuou como assessora. Nesse espaço, foram realizadas entrevistas com os educadores que acompanharam dois bebês com risco de autismo durante o tempo em que frequentaram os berçários. Além disso, efetuou-se a avaliação psicanalítica aos três anos (Kupfer, Jerusalinsky, Infante, \& Bernardino, 2008) das duas crianças, e entrevistas com a educadora do maternal, no intuito de sinalizar, aos pesquisadores, se essas crianças tinham saido do risco do autismo. As memórias evocadas - tanto nas entrevistadas, como na entrevistadora - permitiram pensar o entrelaçamento da escuta da assessoria EP/PI e dos atos educativos para as crianças que se encontravam em risco de autismo. Como esse trabalho foi pensado no a posteriori, em alguns momentos da escrita, os tempos cronológicos se misturam, dando espaços para a narrativa também em tempos lógicos. Dito isso e retomando nossa estória, o entre (Bhabha, 1998) enquanto metodologia de pesquisa foi enlaçado aos quatro tempos da pesquisa.

Primeiro Tempo. A criação do trabalho de assessoria EP/PI no trânsito entre a Educação Especial e a Educação Infantil.

Segundo tempo. A detecção de sinais de autismo em dois bebês de berçário, entre o campo da experiência de assessoramento EP/PI e as memórias da pesquisadora.

Terceiro tempo. A posição inconsciente da pesquisadora em cena, entre as memórias, os giros discursivos de semblante e a avaliação psicanalitica aos três anos (Kupfer et al., 2008).

Quarto tempo: o entre e a escrita da pesquisa no campo da transdisciplinaridade.
Primeiro tempo da história do entre: a criação do trabalho de assessoria EP/PI no trânsito entre a Educação Especial e a Educação Infantil

Este significante metodológico - o entre surgiu na década de 1990, quando a primeira autora ingressou na equipe dos educadores de Educação Especial. Nessa época, junto aos educadores especiais já se pensava em promover um projeto de educação precoce ${ }^{4}$ como modalidade de atendimento terapêutico para crianças de zero a três anos que apresentassem impasses ou dificuldades em sua constituição. A proposta dos atendimentos da educação precoce era que o pedagógico fosse um efeito do trabalho de inclusão e de direcionamento à escola de educação infantil da criança com algum tipo de transtorno do desenvolvimento, deficiência mental, sindrome e/ou atrasos instrumentais.

Já, o trabalho da Assessoria, na Escola de Educação Infantil, tinha a expectativa de que as crianças com problemas de desenvolvimento tivessem um futuro diferente do que o de ser um aluno de uma escola especial. Nessa formatação, o pedagógico enquanto escolar se daria em uma Escola de Educação Infantil e o terapêutico seria nas modalidades de atendimento individual em uma Escola de Educação Especial. Ou seja, quando relatamos sobre a experiência terapêutica, nos referimos ao espaço de atuação profissional na escola especial, visto que lá se rompeu com a exclusão dos ditos deficientes mentais e se ousou montar um local de tratamentos em educação precoce, composto por atendimentos aos bebês portadores de sindromes, deficiências, riscos psíquicos.

Importante ressaltarmos que em 1991, época de implementação da Assessoria da Educação

\footnotetext{
4 Atendimento a bebês com problemas de desenvolvimento de zero a três anos, conjuntamente com os adultos que desempenham as funções materna e paterna para a criança através de um brincar ativo que considere os aspectos globais do desenvolvimento infantil. Essa nomenclatura é utilizada pela equipe de educação especial da EP/PI. Aqui vale referenciar que terapeuta em educação precoce. profissional do atendimento Educacional Especializado do Ministério da Educação Federal (AEE) ou em Estimulação Precoce são similares, utilizados como EP no decorrer do artigo. A diferença é que a terapêutica da educação precoce é uma nomenclatura utilizada pela Secretaria Municipal de Porto Alegre, RS, realizada por educadores especiais, com formação em Estimulação Precoce. Outra diferença é que isso acontece nas escolas especiais em interlocução com serviços da Rede Municipal, de forma gratuita e, concomitantemente, faz-se a Assessoria às escolas infantis. Já a Estimulação Precoce é uma nomenclatura utilizada pelo Centro Lydia Coriat, de Buenos Aires e Porto Alegre. Conforme Coriat e Jerusalinsky (1996), o terapeuta em Estimulação Precoce trata de crianças de zero a três anos, onde a sessão se dá com a criança e os que cumprem as funções materna e paterna. O eixo fundamental é a reestruturação da função materna do cuidador ou do Outro primordial, abarcando os aspectos estruturais e instrumentais de uma criança pequena com transtorno em seu desenvolvimento. Esses autores ressaltam que antes dos três anos, a indiferenciação dos sistemas requer uma especialidade que se ocupe unificadamente dos aspectos instrumentais (brincar, psicomotricidade, linguagem, aprendizagem etc.), os quais estão extremamente ligados aos aspectos estruturais (cognitivo, neurológico, psíquico etc.).
} 
Estruturante nas Escolas de Educação Infantil municipais, havia uma equipe interdisciplinar composta de psicanalistas, psicólogos, fonoaudiólogos e educadores especiais. Essa equipe fazia parte de um departamento que assessorava a educação especial e a regular, mas não havia ninguém que assessorasse a educação infantil no campo da inclusão. Ao relembrarmos esse tempo de criação, ressaltamos que, naquela época, havia muitas ideias educativas, baseadas na perspectiva teórica da Psicanálise e do Construtivismo, calcadas nos ensinos de Sara Pain, Alícia Fernandes, Paulo Freire, Madalena Freire, Ester Grossi e Emilia Ferreiro.

Naquele momento, o campo da Inclusão (campo de incluir as crianças com transtornos de desenvolvimento nos espaços escolares e sociais) abria as portas para a criação de modalidades de atendimentos terapêuticos, de assessorias e de outras possibilidades no campo da Educação Especial. Gurski (2016) assinala que os limites do docente a esse tipo de aluno levam a pensar sobre os caminhos da modernidade na educação especial, os quais sempre ultrapassam as nuances teóricas da Pedagogia Tradicional. Ampliando a questão, a autora destaca que a Educação Especial não pode ficar restrita somente aos aspectos de conteúdos pedagógicos, uma vez que é um campo cheio de paradoxos e cuja insatisfação constante deve ser tomada no efeito da impossibilidade como condição permanente do ato de educar. Desse modo, nos pareceu importante que a Assessoria de EP/PI entrasse em cena, oferecendo aos educadores formações que perpetuassem em possiveis atos de transmissão psicanalítica e não de saber teórico. Relacionamos o trabalho do Psicanalista que atua em escolas ao do assessor de EP/PI, pois ambos são profissionais que transitam nos espaços da educação infantil, colocando-se em estado de disponibilidade para escutar aos educadores, estado esse no qual pode vir a se deparar com algo novo e valioso, onde não se pretendia encontrar (Gurski, 2016).

\section{A construção da Assessoria da Educação Estruturante}

No ano de 2001, foi formalizada pela Secretaria de Educação do município de Porto Alegre a proposta de assessoria denominada como Educação Estruturante. A aposta era que se implementasse um trabalho entre o campo do pedagógico nas Escolas de Educação Infantil em interdisciplinaridade com o terapêutico das Escolas de Educação Especial.

\begin{abstract}
Educação Estruturante é a que propõe ao educador ter seu olhar dirigido aos aspectos diacrônicos da criança - os do desenvolvimento como um todo -, bem como considerar o tempo sincrônico da criança - sua estruturação psíquica e orgânica e a articulação com o desejo. Isso quer dizer que se deve considerar também seu tempo de aprender, suas condições orgânicas e sociais. No planejamento de atividades e intervenções, deve-se pensar também no aluno com transtorno de desenvolvimento e nas questões individuais de cada criança, a fim de serem englobadas no plano de trabalho com o grupo e vice-versa. (Rosa, 2011, p. 104)
\end{abstract}

A partir da leitura desta consigna de trabalho, no processo de assessoramento dos educadores das Escolas de Educação Infantil e das creches conveniadas, pensamos que os paradigmas da Educação Estruturante (Rosa, 2011) compõem junto aos pressupostos das práticas analíticas e educacionais para um caminhar na mesma direção. Nessa perspectiva, educar e tratar se complementam, pois com essas crianças ambos seguem o mesmo princípio: "educar será tratar, e tratar será educar" (Kupfer et al., 2010, p. 296).

\section{Segundo Tempo: a detecção de sinais de autismo em dois bebês de berçário, entre o campo da experiência de Assessoramento EP/PI e as memórias da pesquisadora}

Durante o percurso de Assessoria (em anos anteriores), dois bebês da escola de educação infantil, aqui batizada de João Alhures, ${ }^{5}$ apresentaram sinais de autismo e a assessoria EP/

\footnotetext{
5 Nome fictício dado à escola que se constituiu como cenário desta pesquisa. A pesquisa na escola infantil foi aprovada pelo comitê de ética (do Instituto de Psicologia da UFRGS/2017,sob o título: " As posições discursivas dos educadores que trabalham com bebês que apresentam sinais de autismo precoce "o) e integra a dissertação de mestrado ("O educador e a Assessoria EP/PI de Porto Alegre em cena na prevenção do autismo").
} 
PI acompanhou os educadores do berçário, que eram responsáveis por seus cuidados. Ambos foram nomeados, para fins deste trabalho, de Manoela e Leopoldo. Nessa época, Manoela tinha um ano e três meses e estava sendo investigado o diagnóstico de distrofia muscular. Ela tinha um olhar vago, colocava a mão nos ouvidos por conta dos barulhos, não caminhava, não se sentava e não brincava com seus pares. O segundo bebê. Leopoldo, tinha um ano e dois meses e apresentava epilepsia e o diagnóstico de autismo, de acordo com um laudo neurológico da época. Ele frequentava o berçário (B2), cuja educadora de referência era a professora Idi (nome fictício). Os irmãos de Leopoldo também haviam passado por uma turma com essa mesma educadora.

O trabalho de assessoria EP/PI enquanto Educação Estruturante, nessa escola, propunha observações das cenas educativas, intervenção participante, orientações de posturas, um brincar estruturante (Jerusalinsky, 1999), escuta aos educadores, encaminhamentos à EP/PI das crianças que apresentassem problemas em seu desenvolvimento e formações continuadas. No caso, os educadores assessorados foram os que se interessaram, especificamente, pelas duas crianças, embora outros profissionais da equipe também participassem das conversas e das criações das intervenções estruturantes com a Assessoria.

O educador de referência é um desses atores, que, no campo institucional da Educação Infantil, poderá compor, juntos aos outros adultos implicados no cuidado da criança, uma construção subjetiva para ela. Isso acontecerá não apenas por permanecer de oito a 12 horas fazendo as funções de cuidar e de educar, mas porque as faz referenciando seu desejo de forma não anônima. Durante o processo de assessoria, foi oportunizado aos professores de Manoela e Leopoldo, formações sobre a constituição de um sujeito (Kupfer et al., 2008), o brincar compartilhado (Wanderley, 2013) e os brinquedos estruturantes (Jerusalinsky, 1999). Durante essas atividades formativas, a ideia era a de que eles pudessem se implicar afetivamente com as crianças sustentando seus processos constitutivos.
Terceiro Tempo do entre: a posição inconsciente da pesquisadora em cena, entre as memórias, entrevistas, produções discursivas de semblante e a avaliação psicanalítica aos três anos

Então, a partir do testemunho das ações educativas dos professores dos berçários com Manoela e Leopoldo, durante o trabalho de assessoria e da escrita da pesquisa, passamos a questionar sobre as produções discursivas do educador e do assessor, pensando que, talvez, pudessem ser um lugar de trânsito transdisciplinar (Bhabha, 1998). Nesse sentido, notamos que a Educação Infantil não é composta de apenas uma única modalidade discursiva.

No processo de elaboração da pesquisa, recortamos aquelas experiências de assessoria, como uma produção discursiva - entre uma intervenção participante e uma escuta cuidadosa - que observava os giros discursivos dos educadores. Pensamos que a assessora proporcionava um espaço de fala aos educadores, fazendo perguntas sobre seu fazer em relação às crianças e permitindo que realizassem algumas intervenções. Esse espaço de escuta parecia colocar em questão os laços com as crianças, transferências com os pais, projetos pedagógicos e a interação da criança com seus pais. Pensamos que, no momento que a assessoria de EP/PI se ocupou de acolher as falas dos educadores, ao mesmo tempo, fizesse pedidos para que eles brincassem compartilhadamente (Wanderley, 2013) e se autorizassem a criar e a produzir intervenções que beneficiassem crianças. No âmbito dessas vivências, dizemos semblante de suposto-saber, uma vez que os educadores imaginavam a assessora de EP/PI como alguém que detinha um saber psicanalítico ou psicológico, permitindo assim que trouxessem seus enigmas e questões referente às crianças.

Nessa aposta simbólica de analisar como e o que os educadores dessa escola promoveram como laços subjetivantes com as crianças e como interviram na detecção precoce do autismo, é importante dizer que o que eles ofereceram como produção discursiva foi essencial. É claro que estamos inferindo que tenham produzido marcas 
psiquicas que retiraram os bebês do autismo precoce. Neste rumo, acrescentamos que nada garante que tenham sido eles ou outros, visto que não se trata de uma verdade universal, em que, de agora em diante, todos os educadores infantis tenham ou possam fazer a chamada prevenção da estrutura psíquica denominada autismo. Pareceu-nos, então, algo entre o educador e a criança, e não algo de todos ou nenhum. A possibilidade constitutiva dos educadores de intervirem na subjetividade de bebês e de crianças pequenas com sinais de risco de autismo dependerá da transferência que se estabelece entre ambos e das posições discursivas de semblante postas pelo educador em seus atos de amor, caso a caso.

A transferência (Freud,1932/2010b) pode ser entendida como reedições dos impulsos e das fantasias despertadas e tornadas conscientes no processo de análise, onde os acontecimentos psíquicos ganham vida novamente, como relação atual com a pessoa do analista. Neste sentido, entendemos que se trata de um fenômeno percebido em todas as relações humanas sejam profissionais, hierarquizadas ou amorosas e, para tal, elas também ocorrem entre o educador e a criança com sinais de autismo.

Nesta jornada entre a leitura do assessoramento, a experiência da AP3 - Avaliação Psicanalítica aos 3 anos - (Kupfer et al., 2008) e da escrita do mestrado, delinearam-se os tempos de ver, escutar, ler e compreender os atos e posições dos educadores nos seus efeitos discursivos. A fim de buscar um melhor entendimento, a AP3 é uma avaliação psicanalítica, realizada com crianças de três anos de idade, que tem como objetivo, na sua criação, por Jerusalinsky et al. (2008), a validação do instrumento IRDI (indicadores clínicos de risco psíquico e de desenvolvimento) em crianças desde o nascimento até 18 meses de idade. Neste direcionamento, a AP3 de Manoela e Leopoldo deu-se pela leitura das manifestações da infância e permitiu fazermos uma leitura das manifestações dessas, sinalizando se ainda estavam se deparando com problemas de desenvolvimento ou entraves na sua constituição psíquica. Nessas avaliações, nos deparamos com várias cenas, em que a professora do maternal mostrava-se como alguém que evidenciava um cuidado especial, que poderia ser descrito como encantamento por Manoela, e atenção para Leopoldo.

Nas entrevistas com a educadora do maternal e com as responsáveis pelos berçários, apareceram repetidamente alguns significantes: equipe, bordas, assessoria, apoio, crianças e mães. Tudo isso foi um convite à discursividade e à memória das educadoras, a fim de que se pudesse ler que posições discursivas de semblante, elas ocuparam em relação as duas crianças. O mesmo convite à discursividade foi feito à educadora do Maternal: falar sobre seu encantamento por Manoela e suas intervenções terapêuticas com Leopoldo.

\section{A posição discursiva de semblante das educadoras e da pesquisadora}

A fim de entendermos a posição discursiva de semblante - dos educadores, da assessora e pesquisadora -, foram utilizadas as proposições de Lacan (1969-1970/1992) enquanto laços discursivos e forma de passagens por giros nos quatro discursos. Exemplificamos tais passagens quando as educadoras, na relação com as crianças com sinais de risco de autismo, demandaram respostas no entendimento das mensagens que endereçavam a essas. Também reportamos giros da primeira autora desse escrito nos seus laços com os educadores e na própria torção de assessora à pesquisadora. Neste seguimento, nomearemos o semblante como o agente disparador de cada discurso.

Lacan (1969-1970/1992) toma o discurso como um dispositivo de linguagem que nos permite fazer laços sociais. Esses laços são endereçados a um Outro no discurso, ocorrendo interações entre agente, outro, produção e verdade, formando o que seriam os quatro discursos.

Eis na Figura 1, os matemas dos quatro discursos, segundo Lacan (1969-1970/1992, p. 72): 
Figura 1 - Matemas dos quatro discursos

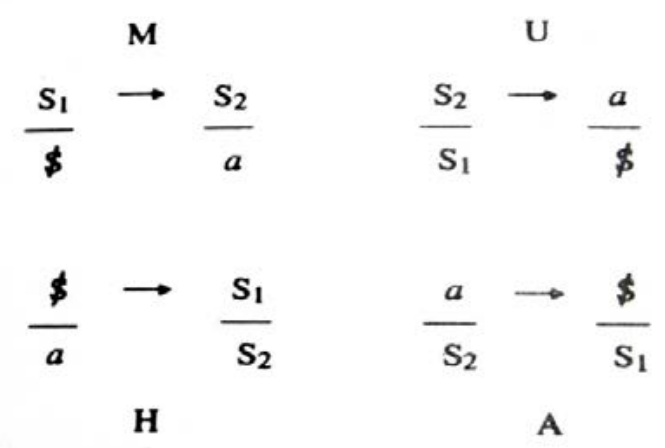

Fonte: Extraido de Lacan (1969-1970/1992, p. 72).

No Discurso do mestre/senhor o semblante se faz presente como o S1 (significante-mestre), quando as educadoras interpretavam e traduziam as mensagens de Manoela e Leopoldo. No discurso do universitário como o S2 (o saber), se fazia presente, por exemplo, quando as educadoras lançavam projetos e conteúdos pedagógicos para as crianças. No discurso da histérica como \$ (sujeito), quando as educadoras buscavam na psicanálise as respostas sobre a constituição psíquica das crianças. Por fim, no do analista o objeto visto como "a" (objeto perdido), quando o assessor thes escutava e apareciam seus atos falhos, perguntas e demandas em relação às crianças. O diferencial nesse último discurso, nos aponta Quinet (2015), é que o analista não faz semblante, ele ocupa a posição de semblante.

Continuando a descrever os impasses de um pesquisador, por vezes parecia um quase isso, surgia algo nas entrelinhas das entrevistas com os educadores e emergiam surpresas, visto que na pesquisa apareceram posições discursivas de semblante que os educadores se ocupavam, nas quais nem se imaginavam. Como demonstram os exemplos a seguir: (a) a educadora do berçário, ao ocupar posição discursiva de semblante da função materna, utilizava a prosódia deixando-se encantar pelo bebê Manuela, chamando-a carinhosa e repetidamente, de "teimosinha", como se fosse a mamãe de Manoela. A bebê passou a olhá-la e a resmungar, como pedindo para que continuasse a cantar; (b) já a educadora do Maternal, instigou Manoela, produzindo espaços de alteridade e separação entre ela e a menina, introduzindo os estagiários de pedagogia para também fazerem atividades com ela, e depois os colegas, a brincarem com a menina. Nestes momentos, oferecia a palavra e antecipava à menina - que outros estariam com ela em atividades e brincadeiras - denotando uma posição discursiva de semblante, referente à função paterna; (c) com Leopoldo, a outra educadora do berçário the dava comida, colo, cuidava de sua higiene e cantava para ele, fazendo vezes de posição discursiva de semblante da função materna; (d) já, a educadora do Maternal fazia em alguns momentos, uma função terapêutica com Leopoldo, visto esse ter sido encaminhado para uma casa- abrigo, devido à destituição do Pátrio poder de sua mãe. A educadora lançou mão, de dar um objeto da escola - que representava que os educadores e colegas estariam com ele -, simbolizado pelo brinquedo dado a ele. A educadora, conversou sobre a nova casa e o preparou para essa separação, referindo aqui sua posição discursiva e terapêutica.

\section{Quarto Tempo do entre: a escrita e} o campo da transdisciplinaridade, 0 educador fazendo giros discursivos de semblante e o pesquisador nos giros e na leitura das surpresas

Muitas surpresas foram surgindo ao logo do desenvolvimento desta pesquisa. Emergiram, no encontro da pesquisadora com as educadoras, memórias de operações e atos educativos que lembravam posições discursivas do discurso do mestre (Kupfer, Bernardino, \& Mariotto, 2014). As educadoras, durante as entrevistas, contavam cenas, nas quais supunham as crianças ( $M a-$ noela e Leopoldo) como sujeitos. Além disso, falavam de brincadeiras de esconde-esconde, do "chiclezinho" que Manoela era com a educadora do maternal e contavam como Leopoldo havia "catado" suas atenções e proteções. Elas também referiram o estabelecimento da rotina escolar como função de separação entre elas e as crianças, bem como relataram suas apostas em receber pedidos e compreensão das mensagens 
de amor que endereçavam às duas crianças. Esses vários giros discursivos de semblante que os educadores produziram, transitando entre o campo do educacional e do terapêutico nos mostravam os efeitos de transmissão da psicanálise e da assessoria de EP/PI denominada Educação Estruturante. O que é importante de ser sinalizando, para exemplificar o quanto o entre estava, desde sempre, ali, mas só pôde emergir no a posteriori, através da torção da posição de assessora para a da pesquisadora atual.

Dessa forma, parecia que a zona de conforto da pesquisadora era no campo da escola de Educação Infantil, o que gerou resistências ao ocupar, não mais a posição discursiva de semblante de assessora e sim a de pesquisadora. Lá naquele campo, a autora reconhecia as práticas e os atos educativos e relançava perguntas sobre o desejo dos educadores em relação às crianças com sinais de autismo. De certa forma, enquanto assessora, havia um suposto-saber, uma vez que as educadoras se sentiam amparadas, se autorizadas a terem uma relação singular e particular com as crianças, dando uma certa suspensão em seus atos pedagógicos. A aposta era de que as educadoras pudessem lançar seus desejos na predileção pela criança com sinais de autismo, mesmo que seguissem se perguntando sobre o que fazer com as outras crianças. Nesse sentido, elas poderão, talvez se encantar e realizar laços educativos, de forma singular e não anônima. Em contraponto a essa zona de conforto da pesquisadora, o espaço da universidade colocou desafios constantes. Dessa forma, o campo educacional em interlocução ao da Psicanálise gerou diversas questões, por serem distintos. A questão que se colocava era como atender aos dois leitores da pesquisa: os educadores e os psicanalistas?

Esse impasse relembra-nos que a Psicanálise é não toda e, ao escrevermos, temos que transitar por esse mestre castrado da incompletude, pois sempre haverá um resto na escrita, uma vez que nem sempre o leitor lerá o que queremos transmitir.
O que nos remete à questão de que se o campo da enunciação é particular, um escrito poderá aflorar e produzirá efeitos, também de forma singular em cada leitor. Será que haverá um entre esses dois campos na pesquisa e nas tessituras de hoje? Se, na pesquisa, achamos os professores fazendo funções semblantes de educadores estruturantes e, também, de terapeutas em educação precoce, será essa uma forma de Educação Terapêutica (Kupfer et al., 2010a), em similaridade à Educação Estruturante (Rosa, 2011). Desta forma, a Educação Estruturante (Rosa, 2011) e a Educação Terapêutica são similares, visto que a direção de ambas é lançada na via de tratar e de educar crianças pequenas, com sinais de autismo, como formas complementares e interdisciplinares. Embora haja esses paradigmas, lembremos: sempre haverá algo que escapa para que seja possivel emergir o desejo e esse se enlace com a demanda do Outro.

Quando falamos em demanda do Outro, nos colocamos a pensar na importância dos personagens que fazem parte do campo do desejo do Outro: a mãe, a educadora, o pai e os adultos significativos que rodeiam a criança. Esses personagens têm uma tarefa muito difícil, que é alienar a criança ao desejo do Outro enquanto operação constituinte. Isso é exatamente o que falha no autismo, quando a criança não se deixa marcar pelos significantes do Outro primordial (que realiza a função materna). Nesta estrutura psíquica, Leda Bernardino $(2014)^{6}$ nos aponta que a criança não se aliena ao campo do Outro. Esta questão, no âmbito da transferência, permeou o início do trabalho da escrita dessa pesquisa, visto que a proposta foi produzir uma dissertação de mestrado que viesse estar no campo do desejo do Outro (universidade, professores e educadores).

Nessa tessitura, o que nos saltou aos olhos foi o entre. O significante entre veio como algo do entrar na pesquisa. A trajetória da pesquisadora elucidava o que aparecia como o entre-lugares: entre os educadores infantis e a Assessoria de EP/PI; entre a Psicanálise e a Educação Infantil;

\footnotetext{
6 Bernardino (2014), nesta obra, remete o termo estruturas psiquicas indecididas para crianças com psicose, mas amplia essa questão ressaltando que na criança pequena, sua posição enquanto sujeito do inconsciente não está decidida, ou seja, não está decidida a posição psicopatológica que pode caracterizá-la. Dessa maneira, subentendemos, que isso se estende a bebês e a crianças pequenas com sinais de autismo.
} 
e entre o campo do educar e o da clínica com criança pequena ou bebê com sinais de risco de autismo. Este trabalho apresentou as possibilidades de advir um sujeito também pela via do campo da Educação Infantil.

Quando se manifestam sinais de exclusão do outro (o semelhante, o par), uma forma de abrir caminhos entre a criança com sinais de Autismo e o Outro primordial (quem faz a função materna para criança), entre ela e o mundo cultural, entre ela e os outros, pode ser a posição discursiva de semblante oferecido por uma educadora, em transferência singularizada e particular com a dita criança que lhe encantou. Ao falarmos que o educador pode produzir posições discursivas de semblante das funções materna, paterna, terapêutica e que, no a posteriori, isso pode compor aberturas para que um sujeito possa advir, põe em perspectiva a complementaridade entre o tratar e o educar. Para tal, assinalamos a importância do papel da assessoria EP/PI para abrir caminhos e dar acesso ao encantamento e singularização dos laços entre os educadores e crianças com sinais de risco de autismo.

\section{Considerações finais}

A relevância dada ao tema do entre, enquanto metodologia, foi devido à possibilidade de produzir um rompimento do binarismo entre Psicanálise e Educação, seja ela infantil ou especial. Visto essas rupturas, criou-se um campo transdisciplinar, similar ao que Bhabha (1998) definiu como entre-lugares. Nesse sentido, o entre-lugares foi o que permitiu na trajetória de assessora no espaço escolar, acompanhar e intervir com crianças com sinais de autismo. A assessora, ela própria, fazia parte de um aparecer e desaparecer na escola de educação infantil, dando lugar para a continuação e a criação de intervenções estruturantes dos educadores.

Nessa delicadeza da tessitura entre esses campos, o ponto que caracterizou a abordagem foi propor um entrelaçamento entre as disciplinas a fim de forçar a lógica binária a se inscrever por outra via de negociação. Nesse sentido, não se tratou do verdadeiro ou do falso, nem da educadora parecer ser a mãe ou pai da criança com sinais de autismo, nem de o educador ter se parecido às vezes com um terapeuta em EP, nem do certo ou do errado, ao ter lançado mão de dispositivos psicanalíticos da constituição do sujeito (Kupfer, 2008). Ou seja, se tratava de intervir, de traduzir, desejar e se transferenciar (Freud, 1932/2010b) com a criança que convocava o educador a algum tipo de produção discursiva de semblante, nos desdobramentos das funções materna, paterna, educativa e, às vezes, terapêutica, a partir da escuta do assessor.

Nesse rumo, as diferenças discursivas conduziram os educadores, sua assessoria e as crianças a movimentos discursivos na construção de algo mais, que remete ao campo do desejo e da demanda. A assessoria, de certo modo, afetou os educadores na transmissão psicanalítica e terapêutica da educação precoce, produzindo um transitar entre um campo e outro de intervenção. Tal trânsito propôs uma reflexão epistemológica sobre o sujeito educador para um lugar enunciativo, de uma prática enunciativa. Para tal, a Educação Infantil surgiu como um lugar de proliferação da transdisciplinaridade, no momento em que os educadores foram tomados pelo desejo de transmissão das quatro operações de um sujeito (Kupfer, et al., 2008), dos brinquedos estruturantes (Jerusalinsky, 1999), dos seus projetos e rotina escolar e de sugestões oferecidas pela assessoria de EP/PI da Educação Estruturante (Rosa,2011). Essa transmissão teve seus efeitos nos laços educativo e amoroso que foram construídos com Manoela e Leopoldo na Escola João Alhures.

Finalizando, assinalamos que os métodos de pesquisa podem tomar seus desvios. No nosso caso, o que antes era para ser uma construção de casos passou a ser um ensaio e, depois, rumou para a história da criação e filiação da assessoria de EP/PI (SMED/POA). Desse modo, trilhamos um recorte da experiência de construção de caso, lida e retomada, a posteriori pela escrita da pesquisa de mestrado. Afinal, se o método pode ser o desvio, concordamos com Walter Benjamim (1933/1994) ao pensar em uma pesquisa como aquilo que se faz, no depois de se ter tropeçado, como que há de movimento não planejado. 


\section{Referências}

Bhabha, H. K. (1998). O Local da Cultura. (M. Ávila, E. L. L. Reis, G. Renate, \& E. Gonçalves, Trad.; 2a. ed.). Belo Horizonte: Editora da UFMG.

Benjamin, W. (1994). Experiência e Pobreza. In W. Benjamin. Magia, Técnica, arte e politica: Obras escolhidas. (S. P. Rouanet, Trad.). São Paulo: Imago. Originalmente publicado em 1933

Bernardino, L. M. F. (2014). A creche, o professor e o desejo. In $10^{\circ}$ Colóquio Internacional do LEPSI. Anais. São Paulo.

Coriat, L., \& Jerusalinsky, A. (1996). Aspectos estruturais e instrumentais do desenvolvimento. Escritos da Criança, $\mathrm{n}^{\circ}$ 4. Porto Alegre: Centro Lydia Coriat.

Diniz, Margareth. (2017). A que visa a escolha de um dispositivo metodológico? In M. Pereira (Org.). Os sintomas na educação de hoje: que fazemos com 'isso'? Belo Horizonte: Scriptum.

Freud, Sigmund. (2010a). Além do principio do prazer. In Freud, S. Obras completas volume 14: História de uma neurose infantil; ("O homem dos lobos"); Além do princípio do prazer e 149 outros textos (1917-1920). (P. C. Souza, Trad.). São Paulo: Companhia das Letras. Trabalho originalmente publicado em 1920.

Freud, S. (2010b). Novas conferências introdutórias à psicanálise. In Freud, Sigmund. Obras completas volume 18: o mal-estar na civilização, novas conferências introdutórias à psicanálise e outros textos (1930-1936). (P. C. Souza, Trad.). São Paulo, SP: Companhia das Letras. Trabalho originalmente publicado em 1932-1933.

Gurski, R. (2016). Formação de professores e transmissão da experiência: Narrar, poetar, profanar. In C. Vasques, \& S. Moschen. (Orgs.). Psicanálise, educação especial e formação de professores: construções em rasuras. Porto Alegre: Evangraf.

Jerusalinsky, A. (1999). Psicanálise e desenvolvimento infantil. (D. Lichtenstein et al, Trad). Porto Alegre: Artes e Ofícios.

Jerusalinsky, A. (2008). Considerações acerca da Avaliação Psicanalítica de Crianças de Três anos - AP3. In R. Lerner, \& M. C. M. Kupfer (Orgs.). Psicanálise com crianças: clínica e pesquisa. São Paulo, SP: Escuta.

Kupfer, M. C. M., Jerusalinsky, A., Infante, D. P., \& Bernardino, L. M. F. (2008). Roteiro para a Avaliação Psicanalítica de Três anos - AP3. In R. Lerner, \&, M. C. M. Kupfer (Orgs.). Psicanálise com crianças: clínica e pesquisa. São Paulo, SP: Escuta.

Kupfer, M. C. M., Bernardino, L. M, F., \& Mariotto, R. M. M. (Orgs.). (2014). Do bebê a sujeito: a metodologia IRDI nas creches. São Paulo: Escuta/Fapesp.

Kupfer, M. C. Ma., Costa, B. H. R., Césaris, D. M. D., \& Cardoso, F. F. (2010, Dezembro). A produção brasileira no campo das articulações entre psicanálise e educação a partir de 1980. Estilos da Clinica, 15(2), p. 284-305. https://doi.org/10.11606/issn.1981-1624.v15i2p284-305
Lacan, J. (1992). O seminário, Livro XVII: O avesso da psicanálise. Rio de Janeiro: Zahar. Originalmente publicado em 1969-1970.

Meira, A. M. G. (2001). Contribuições da Psicanálise para a educação inclusiva. Escritos da Criança: $n^{\circ} 6$. Porto Alegre: Centro Lydia Coriat.

Quinet, A. (2015). Édipo ao pé da letra: Fragmentos da tragédia e psicanálise. Rio de Janeiro: Zahar.

Rosa, D. (2011). O infantil na Psicanálise. Revista da Associação Psicanalitica de Porto Alegre, 1(40), p.104-108.

Schäffer, M. (1999, Janeiro/Junho). Resenha Critica "Entre lugares da cultura: diversidade ou diferença?" Educação e Realidade. Porto Alegre/UFRGS, 24(1), p. 161-167.

Wanderley, D. (2013). Aventuras psicanaliticas com crianças autistas e seus pais. Salvador: Ágalma.

\section{Dorisnei Jornada da Rosa}

Psicóloga, psicanalista, terapeuta em estimulação precoce e assessora de inclusão da Clinica Em Tempo/ POA; mestre em Psicanálise no PPG/Psicanálise: Clínica e Cultura na Universidade federal do Rio Grande do Sul (UFRGS), em Porto Alegre, RS, Brasil.

\section{Andrea Gabriela Ferrari}

Professora do PPG Psicanálise: Clínica e Cultura e do Departamento de Psicanálise e Psicopatologia do Instituto de Psicologia da Universidade Federal do Rio Grande do Sul (UFRGS), em Porto Alegre, RS, Brasil.

\section{Endereço para correspondência}

Dorisnei Jornada da Rosa

Universidade Federal do Rio Grande do Sul

Programa de Pós-graduação em Psicanálise

Rua Ramiro Barcelos, 2600

Santa Cecilia, 90035003

Porto Alegre, RS, Brasil

\section{Andrea Gabriela Ferrari}

Universidade Federal do Rio Grande do Sul

Programa de Pós-graduação em Psicanálise

Rua Ramiro Barcelos, 2600

Santa Cecília, 90035003

Porto Alegre, RS, Brasil 